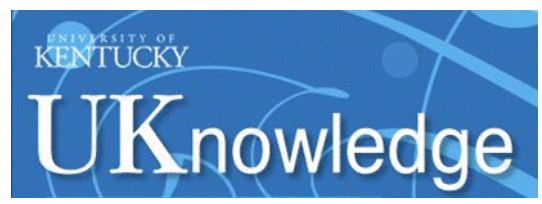

University of Kentucky

UKnowledge

$12-3-2016$

\title{
Perceived Effectiveness and Satisfaction of a Community-Based Positive Youth Development Program: Findings Based on High School Students
}

\author{
Daniel T. L. Shek \\ University of Kentucky \\ Janet T. Y. Leung \\ The Hong Kong Polytechnic University, China \\ Moon Y. M. Law \\ The Hong Kong Polytechnic University, China \\ Kles S. Y. Chan \\ The Hong Kong Polytechnic University, China
}

Follow this and additional works at: https://uknowledge.uky.edu/pediatrics_facpub

Part of the Community-Based Learning Commons, Developmental Psychology Commons, and the Education Commons

Right click to open a feedback form in a new tab to let us know how this document benefits you.

\section{Repository Citation}

Shek, Daniel T. L.; Leung, Janet T. Y.; Law, Moon Y. M.; and Chan, Kles S. Y., "Perceived Effectiveness and Satisfaction of a Community-Based Positive Youth Development Program: Findings Based on High School Students" (2016). Pediatrics Faculty Publications. 282.

https://uknowledge.uky.edu/pediatrics_facpub/282

This Article is brought to you for free and open access by the Pediatrics at UKnowledge. It has been accepted for inclusion in Pediatrics Faculty Publications by an authorized administrator of UKnowledge. For more information, please contact UKnowledge@lsv.uky.edu. 


\title{
Perceived Effectiveness and Satisfaction of a Community-Based Positive Youth
} Development Program: Findings Based on High School Students

\author{
Digital Object Identifier (DOI) \\ https://doi.org/10.1515/ijdhd-2017-7005 \\ Notes/Citation Information \\ Published in International Journal on Disability and Human Development, v. 16, issue 4, p. 367-375. \\ C2017 Walter de Gruyter GmbH, Berlin/Boston.
}

The copyright holder has granted the permission for posting the article here. 
Daniel T.L. Shek*, Janet T.Y. Leung, Moon Y.M. Law and Kies S.Y. Chan

\section{Perceived effectiveness and satisfaction of a community-based positive youth development program: findings based on high school students}

DOI 10.1515/ijdhd-2017-7005

Received July 15, 2016; accepted August 15, 2016; previously published online December 3, 2016

\begin{abstract}
This study examined participants' perceptions of a community-based positive youth development (PYD) program (the Project P.A.T.H.S.) based on the responses of 16,420 junior secondary students who joined the program in 2015. Subjective outcome evaluation approach was adopted to examine the students' views of program content, program instructors, and program effectiveness. Consistent with previous studies, results showed that students generally perceived the program positively, and positive relationships were found amongst the three domains of evaluation. Multiple regression analyses showed that perceived program content and instructor qualities were significant predictors and could explain $35 \%$ of the variance in program effectiveness perceived by the participants. The present findings are basically consistent with previous subjective outcome evaluation findings derived from the school-based and communitybased programs of the Project P.A.T.H.S. in Hong Kong.
\end{abstract}

Keywords: client satisfaction; positive youth development; program effectiveness; Project P.A.T.H.S.; subjective outcome evaluation.

\section{Introduction}

Youth problems such as violence, Internet addiction, and substance abuse are widespread in many contemporary

\footnotetext{
*Corresponding author: Daniel T.L. Shek, Associate Vice President (Undergraduate Programme) and Chair Professor of Applied Social Sciences, The Hong Kong Polytechnic University, Hunghom, Hong Kong, P.R. China; Centre for Innovative Programmes for Adolescents and Families, The Hong Kong Polytechnic University, Hong Kong, P.R. China; Department of Social Work, East China Normal University, Shanghai, P.R. China; Kiang Wu Nursing College of Macau, Macau, P.R. China; and Division of Adolescent Medicine, Department of Pediatrics, Kentucky Children's Hospital, University of Kentucky School of Medicine, Lexington, KY, USA,

E-mail: daniel.shek@polyu.edu.hk

Janet T.Y. Leung, Moon Y.M. Law and Kies S.Y. Chan: Department of Applied Social Sciences, The Hong Kong Polytechnic University, Hong Kong, P.R. China
}

societies. Nowadays, youth problems are becoming more diverse, as well as highly shaped by the mass media and information spread through the Internet. For addressing "traditional” problem behaviors, such as substance abuse, school drop-out, smoking, and early sexual behaviors, many preventive programs have been developed in different countries using different intervention approaches such as psychoeducation and remedial intervention approach [1].

However, youth developmental problems vary across cultures and societies, and they change rapidly according to the value system and social context of each society. In Hong Kong, there are many emerging youth problems such as increasing prevalence of Internet addiction, compensated dating, self-harm behavior, and cyberbullying, which have created challenges for policy makers, parents, teachers, and youth workers in both prevention and remedial work.

Few validated adolescent prevention and development programs [2] have been conducted in Asian communities and these programs have mainly been prevention and single-domain programs such as programs for tackling substance abuse and mood disorders. In fact, most youth programs focusing on prevention of a single problem behavior or a single developmental issue are not ideal because adolescent developmental issues tend to co-exist [3]. In addition, many studies have shown that reduction of risk factors (e.g. poverty, family conflict) and strengthening of protective factors (e.g. family support, self-esteem) could help adolescents adjust to developmental challenges and overcome developmental difficulties [3-5]. Such work suggests that promotion of protective factors such as psychosocial competence and prosocial beliefs may help prevent not just one form of adolescent risk behavior that contributes to adolescent psychological well-being.

To promote holistic adolescent development, which would eventually lead to a reduction of adolescent risk behavior, the Hong Kong Jockey Club Charities Trust initiated a large-scale program named the Project P.A.T.H.S. (Positive Adolescent Training through Holistic Social Program) in collaboration with five universities in Hong Kong [3]. The program utilized principles and concepts of 
the positive youth development (PYD) approach, which highlights the talents, interests, strengths, and potentials of adolescents rather than focusing on treatment and prevention of risky behaviors. In other words, the PYD approach actively promotes human development by considering the potentials and capabilities of each individual human being. There are 15 PYD constructs underpinning the conceptual framework of P.A.T.H.S., which includes self-determination, resilience, spirituality, and other personal capacities such as emotional competence and social competence. These constructs were identified by Catalano et al. [6] after reviewing more than 70 youth development programs in the USA.

The P.A.T.H.S. Project was initially launched in the 2005/2006 academic year and the content was tailored for junior secondary students (i.e. Grade 7-Grade 9). The project was composed of two tiers - Tier 1 was targeted to promote holistic development for all Secondary 1-3 students and Tier 2 program was designed for about onefifth of junior secondary students who have greater psychological needs [7]. The Tier 1 program was a universal curriculum-based program vital to PYD. Junior secondary students attended $10-20 \mathrm{~h}$ of the program based on the PYD constructs. Besides, some developmental issues such as substance abuse, sexuality, and financial management were included in the program content. A training program for program instructors, who were mainly secondary school teachers and social workers, was provided to facilitate the instructors to better understand adolescent development, to prepare relevant knowledge, skills, attitude, and to establish mutual support networks amongst them. The effectiveness of the training program was also rigorously evaluated [8]. As its inception, the project has benefited more than 320 Hong Kong schools with a total of 284,400 students (as in December 2015). From 2013 to 2015, the Project P.A.T.H.S. has been implemented by means of a community-based model. Compared to the school-based model adopted in the previous years, community approach was expected to promote collaborative participation between families, schools, and community organizations, and to increase the diversity of student participants [9].

To understand the impact of the Project P.A.T.H.S., it is important to carry out program evaluation. Client satisfaction evaluation is a common approach widely used in many human service settings such as education, social work, and healthcare [10]. Some researchers believe that client satisfaction serves as an important indicator of the quality and effectiveness of the program and it is an essential way to obtain feedback from clients or program participants for the improvement of service delivery [11]. In this study, we investigated program effectiveness via the client satisfaction approach. Basically, we investigated whether the program participants were satisfied with the program content, instructor, and effectiveness. Besides, the interrelationships amongst these three aspects of satisfaction and predictors of perceived program effectiveness were also studied.

Program evaluation is a process of examining whether a program is generating its desired outcomes or impacts. It is commonly used to indicate whether the program could achieve its goals and objectives and to uncover the unintended effects of the program [11, 12]. Program outcome evaluation focuses on the effectiveness of invention (e.g. teaching and learning activities) and the attainment of program goals. There are many factors affecting the effectiveness of a program. According to Chen [12], program evaluation should include considerations of program implementers (e.g. training, participant-implementer relationships), implementing organization (e.g. schools), service delivery methods (e.g. activity design), and target populations (e.g. students' characteristics). Educational research also suggests that school and classroom contexts, quality of instruction, group activities, teacher behaviors, and consistency of curriculum are factors affecting student learning in school contexts [13]. Generally speaking, program effectiveness cannot be simply evaluated by one single facet of the program. Various aspects of the program should be examined simultaneously to get a comprehensive picture about program effectiveness.

Although the client satisfaction approach is widely adopted in program evaluation, it is argued that students' subjective feedback could not reflect the quality and effectiveness of the program. For example, Mark [14] argued that students in higher education tend to have more satisfaction when perceived performance meets their own expectation. The client satisfaction approach was also criticized because most of the studies found more than $75 \%$ of participants were satisfied with the program [15]. Such high satisfaction rates might be due to biases created by service providers such as using double questions and biased rating scale in the evaluation process [16]. Besides, researchers [11] argued that participant satisfaction of various aspects of a program could not reflect whether the participants changed positively and the changes may not result from the program. Client satisfaction is also not a program outcome in general and participants are always satisfied if the implementation environment of the program could meet their own needs or preferences [17]. The client satisfaction approach was said to be "not able to provide critical evidence of the effectiveness of the program" [18, p. 1].

Despite the arguments against the value of client satisfaction approach, program effectiveness evaluation 
and client satisfaction evaluation share common factors in explaining program outcomes. Elliott [19] found that "student centeredness" and "instructional effectiveness" are the major determinants of students' overall educational experience that influence student satisfaction, which suggests that institutional factors such as instructor's performance might affect client's satisfaction. Another study [20] on client satisfaction found both institutional factors (e.g. the student-teacher relationship) and social factors (e.g. social experience with other students) are significant predictors of client satisfaction, whereas other factors such as student's personal background, learning environment, and commitment to the school should also be considered. These findings are consistent with Chen's study mentioned above [12], which suggests that student characteristics, instructor quality, implementation process, and implementation environment are all predictors of program effectiveness.

Besides, other research findings also suggest that subjective outcome evaluation findings could predict program effectiveness to some degree. Shek [21] attempted to examine the relationship between subjective and objective outcome evaluation based on Chinese secondary students. Results showed that subjective outcome evaluation was highly correlated with objective outcome evaluation where the scores of subjective evaluations were positively associated with the changes in attitude and behavior reported by the program participants. Another study also showed a relationship between client satisfaction ratings and clients' progress of undergoing a child protection program, as well as between the client satisfaction level and their changes in child neglect behavior [22].

Despite the existence of different views on the value of client satisfaction approach, client satisfaction ratings are commonly regarded as an important indicator of program success. Besides looking at the satisfaction levels of program participants, the present study also examined the inter-relationships between different aspects of client satisfaction and the determinants of perceived effectiveness. Regarding the latter, Shek and Sun [23] found that perceived program qualities and program implementers positively predicted program effectiveness ratings. Grade differences of subjective outcome evaluation ratings were also investigated in this study. Previous studies found that younger students always responded more positively as compared to higher grade students [23-25]. These findings raised the question of whether there are grade differences of subjective outcome evaluation in the current study.

In this study, the participants were junior secondary (Grades 7-9) students who had completed the Tier 1 program in the community-based P.A.T.H.S. Project. Several research questions were raised as follows:

1. How do the student participants evaluate the Tier 1 program of the community-based P.A.T.H.S. Project? Based on the past findings [23-25] from different evaluation methods, it was expected that the participants would generally be satisfied with the program (Hypothesis 1).

2. What is the inter-relationship amongst the different aspects of client satisfaction, including perceived program quality, perceived instructor quality, and perceived benefits of the program? Based on the previous studies [23-25], it was predicted that these three aspects of client satisfaction would be significantly correlated amongst themselves (Hypotheses 2a, 2b, and 2c).

3. Is there any difference in the subjective outcome evaluation ratings between the grades? From the previous findings [24, 25], it was hypothesized that students in higher grades would be less satisfied than students in lower grades (Hypothesis 3).

4. Do perceived program quality and perceived instructor quality predict perceived program effectiveness? Based on previous studies [23-25], it was hypothesized that these two factors would predict perceived program effectiveness (Hypothesis 4a and 4b).

\section{Methods}

A total of 21 agencies had implemented the community-based program in 41 projects in community centers or schools located in different districts throughout Hong Kong. To implement the program, 358 social workers and 254 teachers or teaching assistants were involved. In these projects, 18,384 secondary students participated in the program. Amongst them, 14,387 were Secondary 1 students (Grade 7), 2373 were Secondary 2 students (Grade 8), and 1624 were Secondary 3 students (Grade 9).

To facilitate the evaluation process, a briefing was conducted for the agencies before program implementation. After the Tier 1 program was completed, all student participants were invited to fill in the Subjective Outcome Evaluation Form (Form A). During the administration, confidentiality, anonymity, voluntary participation, and freedom to withdraw from the study were emphasized and consent was obtained from all participants. A total of 16,420 questionnaires were returned to the Research Team. Amongst them, 13,003 were Secondary 1 students, 1989 were Secondary 2 students, and 1415 were Secondary 3 students. The overall response rate was $89.32 \%$.

\section{Instruments}

A validated instrument (Form A) was used to assess students' subjective evaluation of the program. It had four parts. Part 1 assessed participants' perceptions of the program content, such as program 
objectives, design, interaction among students, and level of participation (10 items). The second part assessed participants' perceptions of instructor's qualities, such as participation, attitude, and preparation of the instructors (10 items). Participants rated the items in the first two parts on a 6-point Likert scale, where 1 indicated strongly disagree and 6 indicated strongly agree. Part 3 assessed participants' perceptions of the program effectiveness (16 items). A 5-point Likert scale was employed with 1 indicating the program unhelpful and 6 indicating the program really helpful. The final Part consisted of three items, which measured the extent to which the participants would recommend the program to others, the extent to which the participants would participate in similar programs, and their overall satisfaction with the program. There were also four open-ended questions on participants' experiences of the program, such as things that the participant learned from the program and areas where the program should be improved. The open-ended part was not used for analysis in this study because of space limitation.

\section{Data analyses}

Reliability analysis was employed to test the internal consistency of the subjective outcome evaluation measures. Descriptive statistics focusing on the percentage of responses to each item were carried out to reflect the participants' perceptions of the program qualities, instructor qualities, and program effectiveness (Hypothesis 1). For the relationships amongst various aspects of the evaluation measures, Pearson correlation analyses were carried out (Hypothesis 2a, $2 \mathrm{~b}$, and $2 \mathrm{c}$ ). Regarding grade differences (Hypothesis 3), one-way analysis of variance (ANOVA) was used to examine differences in the evaluation ratings amongst students in Secondary 1, 2, and 3 levels. Lastly, multiple regression analyses were conducted to examine whether program effectiveness could be predicted by program content or program instructors (Hypothesis 4). IBM SPSS Statistics for Windows (version 22.0; IBM-SPSS Inc, Chicago, IL, USA) was used for statistical analysis.

\section{Results}

Results on the internal consistency of Form A are shown in Table 1. It was found that the three parts in the questionnaire had high internal consistency. The $\alpha$ values were 0.97 for the 10 questions evaluating program content, 0.98 for the 10 questions evaluating program instructors, and 0.98 for the 16 questions evaluating program effectiveness. Cronbach's $\alpha$ coefficient for the three parts of the evaluation (i.e. 36 items) was 0.98 .

Results on the participants' evaluation of the program content are shown in Table 2. Most of the participants responded positively when evaluating the program content. For example, $89.7 \%$ felt that the activities in the curriculum were planned carefully, 89\% agreed that the classroom atmosphere was very pleasant, 88.8\% reported they experienced much peer interaction amongst students, and $87.9 \%$ agreed that they actively participated in the lessons. The item on evaluating the clarity of curriculum objectives got the highest rating of $89.8 \%$. For the overall perception, $87.8 \%$ reported that on the whole, they liked the curriculum very much.

Table 3 shows the descriptive statistics on the evaluation of program instructors. Amongst the participants in all grade levels, all 10 items got more than $90 \%$ of positive ratings, including instructors' mastery of curriculum (91.2\%), preparation for the lessons (91.7\%), teaching skills (91.3\%), and professional attitudes (91.6\%). The participants also evaluated the instructors as very involved (91.9\%), were able to encourage students' participation (91.7\%), cared for the students $(90.9 \%)$, and had much interaction with them (90.9\%). The overall evaluation received the highest positive rating of $92.2 \%$, reflecting the high satisfaction of the performance of program instructors.

Regarding the evaluation of program effectiveness, most of the participants perceived the program to be effective in fostering the specific qualities of PYD (Table 4). For instance, the participants agreed that the program could strengthen their bonding with others $(87.7 \%)$ and resilience (89.6\%), improve their ability in emotional expression and management (89.9\%), increase self-confidence $(89.3 \%)$, and increase selfawareness (90.4\%). The items received the highest ratings were "ability to distinguish between the good and the bad" (91.8\%) and "increase competence in

Table 1: Mean, standard deviations, Cronbach's $\alpha$ s, and mean of inter-item correlations.

\begin{tabular}{|c|c|c|c|c|c|c|c|c|}
\hline & \multicolumn{2}{|r|}{ S1 } & \multicolumn{2}{|r|}{ S2 } & \multicolumn{2}{|r|}{ S3 } & \multicolumn{2}{|r|}{ Overall } \\
\hline & $M(S D)$ & $\alpha\left(\right.$ Mean $\left.^{\mathrm{a}}\right)$ & $M(S D)$ & $\alpha\left(M_{e a n}^{a}\right)$ & $M(S D)$ & $\alpha\left(M_{e a n}^{a}\right)$ & $M(S D)$ & $\alpha\left(M_{e a n}^{a}\right)$ \\
\hline Program content (10 items) & $4.62(0.95)$ & $0.97(0.75)$ & $4.58(0.90)$ & $0.97(0.74)$ & $4.59(0.85)$ & $0.96(0.69)$ & $4.62(0.94)$ & $0.97(0.75)$ \\
\hline Program instructors (10 items) & $4.80(0.95)$ & $0.98(0.81)$ & $4.75(0.91)$ & $0.98(0.81)$ & $4.77(0.86)$ & $0.97(0.76)$ & $4.79(0.94)$ & $0.98(0.81)$ \\
\hline Program effectiveness (16 items) & $3.81(0.88)$ & $0.98(0.76)$ & $3.61(0.85)$ & $0.98(0.76)$ & $3.71(0.84)$ & $0.98(0.71)$ & $3.78(0.86)$ & $0.98(0.75)$ \\
\hline Total effectiveness ( 36 items) & $4.30(0.79)$ & $0.98(0.58)$ & $4.19(0.74)$ & $0.98(0.55)$ & $4.22(0.73)$ & $0.98(0.53)$ & $4.28(0.78)$ & $0.98(0.57)$ \\
\hline
\end{tabular}

S1, Secondary 1 level; S2, Secondary 2 level; S3, Secondary 3 level. aMean inter-item correlations. 
Table 2: Descriptive statistics of the participants' evaluations on the program content.

\begin{tabular}{|c|c|c|c|c|c|c|c|c|}
\hline & \multicolumn{8}{|c|}{ Respondents with positive responses (Options 4-6) } \\
\hline & \multicolumn{2}{|r|}{ S1 } & \multicolumn{2}{|r|}{$\mathbf{S 2}$} & \multicolumn{2}{|r|}{ S3 } & \multicolumn{2}{|c|}{ Overall } \\
\hline & $\mathbf{n}$ & $\%$ & $\mathbf{n}$ & $\%$ & $\mathbf{n}$ & $\%$ & $\mathbf{n}$ & $\%$ \\
\hline 1. The objectives of the curriculum are very clear & 11,606 & 89.9 & 1757 & 89.7 & 1253 & 89.4 & 14,628 & 89.8 \\
\hline 2. The design of the curriculum is very good & 11,523 & 89.2 & 1756 & 89.5 & 1242 & 89.0 & 14,532 & 89.2 \\
\hline 3. The activities were carefully planned & 11,584 & 89.7 & 1762 & 90.0 & 1249 & 89.3 & 14,607 & 89.7 \\
\hline 4. The classroom atmosphere was very pleasant & 11,440 & 88.7 & 1762 & 90.0 & 1261 & 90.3 & 14,475 & 89.0 \\
\hline 5. There was much peer interaction amongst the students & 11,440 & 88.8 & 1730 & 88.7 & 1250 & 89.5 & 14,432 & 88.8 \\
\hline $\begin{array}{l}\text { 6. I participated actively during lessons (including discussions, } \\
\text { sharing, games, etc.) }\end{array}$ & 11,338 & 87.8 & 1700 & 86.8 & 1249 & 89.6 & 14,298 & 87.9 \\
\hline 7. I was encouraged to do my best & 11,262 & 87.3 & 1654 & 84.4 & 1235 & 88.5 & 14,162 & 87.1 \\
\hline $\begin{array}{l}\text { 8. The learning experience I encountered enhanced my interest } \\
\text { towards the lessons }\end{array}$ & 11,271 & 87.5 & 1685 & 86.1 & 1228 & 88.0 & 14,194 & 87.3 \\
\hline 9. Overall speaking, I have a very positive evaluation of the program & 11,342 & 87.9 & 1708 & 87.3 & 1249 & 89.5 & 14,308 & 87.9 \\
\hline 10. On the whole, I like this curriculum very much & 11,314 & 87.8 & 1713 & 87.4 & 1242 & 89.0 & 14,279 & 87.8 \\
\hline
\end{tabular}

All items are on a 6-point Likert scale with $1=$ strongly disagree, 2 = disagree, $3=$ slightly disagree, $4=$ slightly agree, $5=$ agree, $6=$ strongly agree. Only respondents with positive responses (Options 4-6) are shown in the table. S1, Secondary 1 level; S2, Secondary 2 level; S3, Secondary 3 level.

Table 3: Descriptive statistics of the participants' evaluations of the program instructors.

\begin{tabular}{|c|c|c|c|c|c|c|c|c|}
\hline & \multicolumn{8}{|c|}{ Respondents with positive responses (Options 4-6) } \\
\hline & \multicolumn{2}{|r|}{ S1 } & \multicolumn{2}{|r|}{ S2 } & \multicolumn{2}{|r|}{ S3 } & \multicolumn{2}{|c|}{ Overal } \\
\hline & $\mathbf{n}$ & $\%$ & $\mathbf{n}$ & $\%$ & $\mathbf{n}$ & $\%$ & $\mathbf{n}$ & $\%$ \\
\hline 1. The instructor(s) had a good mastery of the curriculum & 11,760 & 91.1 & 1793 & 91.3 & 1290 & 92.2 & 14,852 & 91.2 \\
\hline 2. The instructor(s) was well prepared for the lessons & 11,833 & 91.6 & 1807 & 92.0 & 1287 & 92.1 & 14,937 & 91.7 \\
\hline 3. The instructor(s)' teaching skills were good & 11,778 & 91.3 & 1794 & 91.5 & 1279 & 91.8 & 14,861 & 91.3 \\
\hline 4. The instructor(s) showed good professional attitudes & 11,812 & 91.6 & 1802 & 91.9 & 1283 & 91.8 & 14,907 & 91.6 \\
\hline 5. The instructor(s) was very involved & 11,841 & 91.8 & 1811 & 92.3 & 1297 & 93.0 & 14,858 & 91.9 \\
\hline 6. The instructor(s) encouraged students to participate in the activities & 11,831 & 91.7 & 1800 & 91.6 & 1294 & 92.6 & 14,934 & 91.7 \\
\hline 7. The instructor(s) cared for the students & 11,738 & 91.0 & 1776 & 90.4 & 1269 & 91.0 & 14,792 & 90.9 \\
\hline 8. The instructor(s) was ready to offer help to students when needed & 11,861 & 91.9 & 1804 & 91.9 & 1279 & 91.8 & 14,954 & 91.9 \\
\hline 9. The instructor(s) had much interaction with the students & 11,746 & 91.0 & 1781 & 90.7 & 1268 & 90.7 & 14,803 & 90.9 \\
\hline 10. Overall speaking, I have a very positive evaluation of the instructors & 11,890 & 92.1 & 1816 & 92.5 & 1302 & 93.1 & 15,017 & 92.2 \\
\hline
\end{tabular}

All items are on a 6-point Likert scale with $1=$ strongly disagree, 2 =disagree, $3=$ slightly disagree, $4=$ slightly agree, $5=$ agree, $6=$ strongly agree. Only respondents with positive responses (Options 4-6) are shown in the table. S1, Secondary 1 level; S2, Secondary 2 level; S3, Secondary 3 level.

making sensible and wise choices" (91.7\%). There were $91.7 \%$ of the participants agreeing that the program enriched their overall development.

Table 5 shows the participants' responses to the rest of the items in Form A. Specifically, 85.2\% of the participants responded that they would suggest their friends to join the program, $76.1 \%$ said they were willing to participate in similar program again in future, and $95 \%$ indicated that they were satisfied with the program. These results suggest that participants generally viewed the program positively.

To understand the relationships amongst the three aspects of subjective evaluation, Pearson correlation analyses were conducted (Table 6). Results showed that the three aspects were significantly correlated amongst themselves. The relationship between perceived program content and perceived program instructor was the strongest $(r=0.79, p<0.001)$. Perceived program effectiveness was also significantly related to program content $(r=0.58, p<0.001)$ and program instructors $(\mathrm{r}=0.51, \mathrm{p}<0.001)$.

Several one-way ANOVAs were conducted to analyze grade differences in the subjective outcome evaluation ratings, with grade as the independent variable and perceived program content (10 items), instructors 
Table 4: Descriptive statistics of the participants' evaluations of the program effectiveness.

\begin{tabular}{|c|c|c|c|c|c|c|c|c|}
\hline \multirow{3}{*}{$\begin{array}{l}\text { The extent to which the course (i.e. the program that all students have joined) } \\
\text { has helped you }\end{array}$} & \multicolumn{8}{|c|}{ Respondents with positive responses (Options 3-5) } \\
\hline & \multicolumn{2}{|r|}{ S1 } & \multicolumn{2}{|r|}{ S2 } & \multicolumn{2}{|r|}{ S3 } & \multicolumn{2}{|c|}{ Overall } \\
\hline & $\mathbf{n}$ & $\%$ & $\mathbf{n}$ & $\%$ & $\mathbf{n}$ & $\%$ & $\mathbf{n}$ & \% \\
\hline 1. It has strengthened my bonding with teachers, classmates, and my & 11,084 & 88.0 & 1660 & 86.4 & 1184 & 86.9 & 13,941 & 87.7 \\
\hline 2. It has strengthened my resilience in adverse conditions & 11,325 & 89.9 & 1712 & 88.9 & 1207 & 88.4 & 14,257 & 89.6 \\
\hline 3. It has enhanced my social competence & 11,472 & 91.2 & 1732 & 89.7 & 1221 & 89.8 & 14,438 & 90.9 \\
\hline 4. It has improved my ability in handling and exp & 11,347 & 88.0 & 1701 & 88.6 & 1201 & 88.3 & 14,262 & 89.9 \\
\hline 5. It has enhanced my cognitive competence & 11,412 & 90.7 & 1731 & 89.9 & 1214 & 89.1 & 14,370 & 90.5 \\
\hline 6. My ability to resist harmful influences has been improved & 11,492 & 91.3 & 1742 & 90.7 & 1214 & 89.4 & 14,461 & 91.1 \\
\hline 7. It has strengthened my ability to distinguish between the good and the bad & 11,594 & 92.1 & 1752 & 91.0 & 1225 & 90.1 & 14,584 & 91.8 \\
\hline 8. It has increased my competence in making sensible and wise choices & 11,580 & 92.0 & 1747 & 90.8 & 1229 & 90.5 & 14,569 & 91.7 \\
\hline 9. It has helped me to have life reflections & 11,313 & 90.0 & 1698 & 88.7 & 1208 & 89.3 & 14,232 & 89.8 \\
\hline 10. It has reinforced my self-confidence & 11,289 & 89.7 & 1683 & 87.4 & 1204 & 88.5 & 14,189 & 89.3 \\
\hline 11. It has increased my self-awareness & 11,413 & 90.7 & 1710 & 89.1 & 1211 & 89.0 & 14,347 & 90.4 \\
\hline 12. It has helped me to face the future with a positive attitude & 11,432 & 90.9 & 1721 & 89.6 & 1232 & 90.6 & 14,398 & 90.7 \\
\hline 13. It has helped me to cultivate compassion and care about others & 11,455 & 91.1 & 1714 & 89.1 & 1221 & 89.6 & 14,403 & 90.7 \\
\hline 14. It has encouraged me to care about the community & 11,337 & 90.2 & 1700 & 88.8 & 1206 & 88.6 & 14,256 & 89.9 \\
\hline 15. It has promoted my sense of responsibility in serving the society & 11,395 & 90.5 & 1691 & 88.3 & 1200 & 88.2 & 14,299 & 90.0 \\
\hline 16. It has enriched my overall development & 11,568 & 91.9 & 1739 & 90.7 & 1239 & 91.0 & 14,559 & 91.7 \\
\hline
\end{tabular}

All items are on a 5 -point Likert scale with $1=$ unhelpful, $2=$ not very helpful, $3=$ slightly helpful, $4=$ helpful, $5=$ very helpful. Only respondents with positive responses (Options 3-5) are shown in the table. S1, Secondary 1 level; S2, Secondary 2 level; S3, Secondary 3 level.

(10 items), program effectiveness (16 items), and total scale (36 items) to be the dependent variables. Results in Table 7 showed that participants in different grades differed in their perception of program effectiveness (16 items $)(\mathrm{F}=49.74, \mathrm{p}<0.001)$ and total program satisfaction $(\mathrm{F}=19.29, \mathrm{p}<0.001)$. Post-hoc comparison tests with Bonferroni correction further indicated that Secondary 1 students had significantly higher ratings on perceived program effectiveness and total program satisfaction compared to Secondary 2 and 3 participants. Secondary 2 students' ratings were also different from those of Secondary 3 students on the rating of perceived program effectiveness.

Multiple regression analyses were further employed to examine to what extent program content and program instructors predicted perceived program effectiveness (Table 8). Evaluation of program content was found to be a strong predictor for perceived program effectiveness among all the three grades (Secondary 1: $\beta=0.48$, $\mathrm{p}<0.001$; Secondary 2: $\beta=0.40, \mathrm{p}<0.001$; Secondary 3: $\beta=0.49, p<0.001$; overall: $\beta=0.47, p<0.001)$. Besides, perception of program instructors also positively predicted perceived program effectiveness (Secondary 1: $\beta=0.14, p<0.001$; Secondary 2: $\beta=0.20, p<0.001$; Secondary 3: $\beta=0.14, p<0.001$; overall: $\beta=0.15, p<0.001$ ). These findings showed that subjective evaluation of program content and instructors were predictors of perceived effectiveness and they explained $35 \%$ of the variance in perceived program effectiveness amongst all the three grades of students.

\section{Discussion}

The present study examined the views of the students on the Tier 1 program of the community-based Project P.A.T.H.S. using subjective outcome evaluation approach. Nearly $90 \%$ of the program participants returned the questionnaire, which covers perceived program content, instructors, and effectiveness. There are several strengths of the present study. First, the study employed a very large sample size $(n=10,000+)$ which is rare in program evaluation studies. The large sample size helps to make the statistical findings more stable and accurate. Second, the study employed validated instruments that have been tested repeatedly. The instruments showed good psychometric properties including test-retest reliability and construct validity $[26,27]$. Third, the study examined the relationships amongst different aspects of client satisfaction and investigated how perceived program content and instructor predicted the overall perception of program effectiveness, which is not commonly examined in the evaluation literature. It demonstrated the usefulness of subjective outcome evaluation account for program effectiveness and depicted the influence of different factors 
Table 5: Other aspects of subjective outcome evaluation based on the participants' perception.

If your friends have needs and conditions similar to yours, will you suggest him/her to join this course?

\begin{tabular}{|c|c|c|c|c|c|c|c|}
\hline \multicolumn{8}{|c|}{ Respondents with positive responses (Options 3-4) } \\
\hline \multicolumn{2}{|l|}{ S1 } & \multicolumn{2}{|r|}{$\mathbf{S 2}$} & \multicolumn{2}{|r|}{ S3 } & \multicolumn{2}{|c|}{ Overall } \\
\hline $\mathbf{n}$ & $\%$ & $\mathbf{n}$ & $\%$ & $\mathbf{n}$ & $\%$ & $\mathbf{n}$ & $\%$ \\
\hline 9943 & 85.1 & 1607 & 84.3 & 1143 & 87.9 & 12,699 & 85.2 \\
\hline
\end{tabular}

The item is on a 4-point Likert scale with $1=$ definitely will not suggest, 2 = will not suggest, 3 = will suggest, 4 = definitely will suggest. Only respondents with positive responses (Options 3-4) are shown in the table. S1, Secondary 1 level; S2, Secondary 2 level; S3, Secondary 3 level.

Will you participate in similar courses again in the future?

\begin{tabular}{|c|c|c|c|c|c|c|c|}
\hline \multicolumn{8}{|c|}{ Respondents with positive responses (Options $3-4$ ) } \\
\hline \multicolumn{2}{|l|}{ S1 } & \multicolumn{2}{|r|}{$\mathbf{S 2}$} & \multicolumn{2}{|r|}{ S3 } & \multicolumn{2}{|c|}{ Overal } \\
\hline $\mathbf{n}$ & $\%$ & $\mathbf{n}$ & $\%$ & $\mathbf{n}$ & $\%$ & $\mathbf{n}$ & $\%$ \\
\hline 8897 & 75.8 & 1441 & 75.1 & 1043 & 79.9 & 11,385 & 76.1 \\
\hline
\end{tabular}

The item is on a 4-point Likert scale with $1=$ definitely will not participate, 2 = will not participate, $3=$ will participate, $4=$ definitely will participate. Only respondents with positive responses (Options 3-4) are shown in the table. S1, Secondary 1 level; S2, Secondary 2 level; S3, Secondary 3 level.

On the whole, are you satisfied with this course?

\begin{tabular}{|c|c|c|c|c|c|c|c|}
\hline \multicolumn{8}{|c|}{ Respondents with positive responses (Options 4-6) } \\
\hline \multicolumn{2}{|l|}{ S1 } & \multicolumn{2}{|r|}{ S2 } & \multicolumn{2}{|r|}{ S3 } & \multicolumn{2}{|c|}{ Overall } \\
\hline $\mathrm{n}$ & $\%$ & $n$ & $\%$ & $n$ & $\%$ & $n$ & $\%$ \\
\hline 12,166 & 94.78 & 1884 & 95.7 & 1334 & 95.8 & 15,393 & 95.0 \\
\hline
\end{tabular}

All items are on a 6-point Likert scale with $1=$ very dissatisfied, $2=$ moderately dissatisfied, $3=$ slightly dissatisfied, $4=$ satisfied, $5=$ moderately satisfied, $6=$ very satisfied. Only respondents with positive responses (Options 4-6) are shown in the table. S1, Secondary 1 level; S2, Secondary 2 level; S3, Secondary 3 level.

Table 6: Pearson correlations amongst program content, instructors, and effectiveness.

\begin{tabular}{lccr}
\hline Variable & $\mathbf{1}$ & $\mathbf{2}$ & $\mathbf{3}$ \\
\hline 1. Program content (10 items) & - & & \\
2. Program instructors (10 items) & $0.79^{\mathrm{a}}$ & - & \\
3. Program effectiveness (16 items) & $0.58^{\mathrm{a}}$ & $0.51^{\mathrm{a}}$ & - \\
\hline${ }^{\mathrm{a}} \mathrm{p}<0.001$. & &
\end{tabular}

that could help build up models of outcome evaluation. Last but not least, the study examined the rates of satisfaction across different grades, which helped evaluate the
Table 7: One-way ANOVA comparing the evaluations of the program of participants in different grade levels.

\begin{tabular}{|c|c|c|c|c|c|}
\hline & & $\begin{array}{l}\text { Sum of } \\
\text { squares }\end{array}$ & & $\begin{array}{l}\text { Mean } \\
\text { square }\end{array}$ & $F$ \\
\hline $\begin{array}{l}\text { Program } \\
\text { content }\end{array}$ & $\begin{array}{l}\text { Between groups } \\
\text { Within groups } \\
\text { Total }\end{array}$ & $\begin{array}{r}3.50 \\
14,065.32 \\
14,068.82\end{array}$ & $\begin{array}{r}2 \\
16,011 \\
16,013\end{array}$ & $\begin{array}{l}1.75 \\
0.88\end{array}$ & 1.99 \\
\hline $\begin{array}{l}\text { Program } \\
\text { instructors }\end{array}$ & $\begin{array}{l}\text { Between groups } \\
\text { Within groups } \\
\text { Total }\end{array}$ & $\begin{array}{l}4.72 \\
14,158.29 \\
14,163.00\end{array}$ & $\begin{array}{r}2 \\
16,097 \\
16,099\end{array}$ & $\begin{array}{l}2.36 \\
0.88\end{array}$ & 2.68 \\
\hline $\begin{array}{l}\text { Program } \\
\text { effectiveness }\end{array}$ & $\begin{array}{l}\text { Between groups } \\
\text { Within groups } \\
\text { Total }\end{array}$ & $\begin{array}{r}75.84 \\
11,812.37 \\
11,888.21\end{array}$ & $\begin{array}{r}2 \\
15,495 \\
15,497\end{array}$ & $\begin{array}{r}37.92 \\
0.76\end{array}$ & $49.74^{\mathrm{a}}$ \\
\hline $\begin{array}{l}\text { Total } \\
\text { effectiveness }\end{array}$ & $\begin{array}{l}\text { Between groups } \\
\text { Within groups } \\
\text { Total }\end{array}$ & $\begin{array}{r}23.30 \\
9089.30 \\
9112.61\end{array}$ & $\begin{array}{r}2 \\
15,047 \\
15,049\end{array}$ & $\begin{array}{r}11.65 \\
0.60\end{array}$ & $19.29^{\mathrm{a}}$ \\
\hline$<0.001$ & & & & & \\
\hline & & Post hoc tests & s (multiple & compa & arisons) \\
\hline $\begin{array}{l}\text { Dependent } \\
\text { variable }\end{array}$ & $\begin{array}{r}\text { (I) } \\
\text { Grade }\end{array}$ & $\begin{array}{r}(J) \\
\text { irade }\end{array}$ & $\begin{array}{r}\text { Mean } \\
\text { arence (I-J) }\end{array}$ & & td. error \\
\hline $\begin{array}{l}\text { Program } \\
\text { content }\end{array}$ & $\begin{array}{l}\text { S1 } \\
\text { S2 }\end{array}$ & $\begin{array}{l}\text { S2 } \\
\text { S3 } \\
\text { S3 }\end{array}$ & $\begin{array}{r}0.04 \\
0.03 \\
-0.01\end{array}$ & & $\begin{array}{l}0.02 \\
0.03 \\
0.03\end{array}$ \\
\hline $\begin{array}{l}\text { Program } \\
\text { instructors }\end{array}$ & $\begin{array}{l}\text { S1 } \\
\text { S2 }\end{array}$ & $\begin{array}{l}\text { S2 } \\
\text { S3 } \\
\text { S3 }\end{array}$ & $\begin{array}{r}0.05 \\
0.03 \\
-0.01\end{array}$ & & $\begin{array}{l}0.02 \\
0.03 \\
0.03\end{array}$ \\
\hline $\begin{array}{l}\text { Program } \\
\text { effectiveness }\end{array}$ & $\begin{array}{l}\text { S1 } \\
\text { S2 }\end{array}$ & $\begin{array}{l}\text { S2 } \\
\text { S3 } \\
\text { S3 }\end{array}$ & $\begin{array}{r}0.20^{\mathrm{a}} \\
0.11^{\mathrm{a}} \\
-0.09^{\mathrm{b}}\end{array}$ & & $\begin{array}{l}0.02 \\
0.03 \\
0.03\end{array}$ \\
\hline $\begin{array}{l}\text { Total } \\
\text { effectiveness }\end{array}$ & S1 & $\begin{array}{l}\text { S2 } \\
\text { S3 } \\
\text { S3 }\end{array}$ & $\begin{array}{r}0.11^{\mathrm{a}} \\
0.07^{\mathrm{b}} \\
-0.04\end{array}$ & & $\begin{array}{l}0.02 \\
0.02 \\
0.03\end{array}$ \\
\hline
\end{tabular}

S1, Secondary 1 level; S2, Secondary 2 level; S3, Secondary 3 level. ${ }^{\mathrm{a}} \mathrm{p}<0.001 ;{ }^{\mathrm{b}} \mathrm{p}<0.01$.

applicability of the program to adolescents across 3 years of implementation.

The generally high satisfaction rate (over $85 \%$ ) found in this study supported Hypothesis 1. It replicated the evaluation findings from both initial implementation phase and the extension phase of the project [23-25]. The program participants generally had very positive perception toward the program content, instructors, and program effectiveness, suggesting that the program was well-designed and delivered to the students in satisfactory ways. It is noteworthy that most of the participants perceived the program as effective in promoting different aspects of their development. Most of the participants 
Table 8: Multiple regression analyses predicting program effectiveness by program content and instructors.

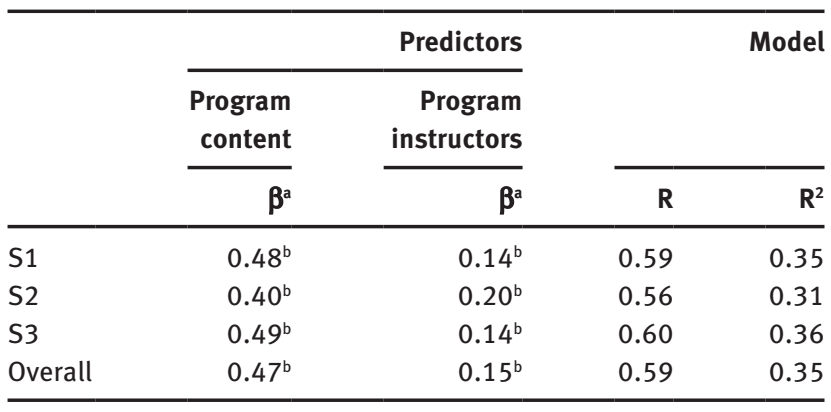

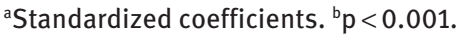

(more than 75\%) agreed that they would recommend the program to their friends and were willing to attend the program again. In short, the findings are generally in line with the previous studies [23-25]. The consistent findings throughout the years suggested that adolescents had a favorable evaluation of the P.A.T.H.S. Program.

Amongst the three aspects of the evaluation, the participants reported the highest satisfaction rates in the program instructor domain. All the items under the aspect of instructor evaluation received more than $90 \%$ of satisfaction rate, implying that the instructors performed well in delivering the program. The findings give support to the effectiveness of the related training programs provided to the potential instructors $[8,25]$. The instructors had evaluated the training program that could enhance their self-confidence, self-reflection, and efficacy in program delivery [8]. Similarly, the results of the current study found that the students agreed the instructors had good performance such as mastery of the curriculum, good professional attitudes, and teaching skills.

Regarding the inter-relationship amongst the three aspects of client satisfaction, Pearson correlation analyses found significant positive relationships. The findings support Hypotheses 2a, 2b, and 2c. The results are generally consistent with previous studies in both initial implementation phase and extension phase [23-25], which found the program quality and program instructor to be closely associated. A possible explanation for this result may be that instructor qualities like mastery of the curriculum could predominantly decide the program content received by the students.

As for the difference between grades in subjective outcome ratings, the present findings are different from the previous studies [24, 25]. In the satisfaction rate of program content and instructor, there was no significant difference amongst the three grades. The results are inconsistent with previous findings on subjective outcome evaluation [24,
25], which found that younger students generally evaluated the program more positive in all aspects than did older students. However, the present study found significant grade differences in the evaluation of perceived program effectiveness and total effectiveness. Secondary 1 students evaluated the program as more effective than Secondary 2 and 3 students, where Secondary 2 students perceived the program as least effective. Regarding program effectiveness, the higher effectiveness reported by Secondary 1 students could be explained by their receptiveness to school involvement. Higher grade students were increasingly more susceptible to peer influence but less receptive to school involvement [28]. They might be more critical and skeptical to what they learned while for younger students it is easier to make changes simply for classroom learning. Of course, further research is needed to explain the contributing factors of grade difference in detail.

Consistent with our predictions (Hypothesis 4), multiple regression analyses showed that both perceived program quality and instructor quality were significant predictors of perceived program effectiveness. Results showed that the predictive power of perceived program quality and instructor quality was moderate amongst all the three grades $(31 \%-36 \%)$. The results are similar to former studies $[25,29]$. However, the current study could not replicate the high predictive power (more than $60 \%$ ) found in other two earlier studies [23, 24]. Further studies are needed to explain the different findings as well as explore the factors interacting with program effectiveness.

In conclusion, the study showed that the program participants were overall satisfied with the Tier 1 program in all the three aspects of evaluation including program content, program instructors, and program effectiveness. Results also found that perceived content and instructor quality could predict perceived program effectiveness. The major results of the study are consistent with previous studies [23-25] while attention should also be paid to the minor differences such as the grade difference found in perceived program effectiveness but not in perceived program and instructor quality. These new findings might imply the emerging needs of youth which consequently affect the applicability and effectiveness of PYD program.

Despite the positive results of the subjective outcome evaluation, the current study has several limitations. First, the data reported in this study were mainly from quantitative data of client satisfaction evaluation. Obviously, it would be helpful to further understand the in-depth learning experiences of the students. Second, behavioral changes such as improvement of peer relationship were not assessed in this study. It is suggested that additional evaluation effort should be made to support the effectiveness of the program in the 
future, such as the use of objective outcome evaluation. Objective measures such as engagement in problem behaviors, academic performance, or participation in community services could be included in the future evaluation. Third, besides program content and instructors, other factors, which accounted for more than $60 \%$ of the variance in program effectiveness, were not covered in the study. As suggested by Chen [12], the characteristics of students and the learning environment may also affect program effectiveness. Group comparison studies could be employed to figure out other factors that are crucial to the program effectiveness. Fourth, this study was a one-off cross-sectional evaluation study, which could not provide information about long-term changes in the program participants. Further research such as longitudinal studies and case studies could be used to evaluate the changes of PYD qualities amongst the students. Despite the above limitations, the findings in this study still substantiate the effectiveness of the Tier 1 program of the community-based P.A.T.H.S. Project based on the subjective outcome evaluation approach.

Acknowledgments: The present article and the Project P.A.T.H.S. are financially supported by the Hong Kong Jockey Club Charities Trust.

\section{References}

1. Gottfredson DC, Wilson DB, Najaka SS. School-based crime prevention. In: Farrington DP, Sherman LW, Welsh B, Mackenzie DL, editors. Evidence-based crime prevention. London: Harwood Academic, 2002:56-164.

2. Shek DT. A review of validated youth prevention and positive youth development programs in Asia. Int J Adolesc Med Health 2011;23:317-24.

3. Shek DT. Adolescent developmental issues in Hong Kong: relevance to positive youth development programs in Hong Kong. Int J Adolesc Med Health 2006;18:341-54.

4. Resnick MD, Ireland M, Borowsky I. Youth violence perpetration: what protects? what predicts? findings from the National Longitudinal Study of Adolescent Health. J Adolesc Health 2004;35:1-10.

5. Lösel F, Farrington DP. Direct protective and buffering protective factors in the development of youth violence. Am J Prev Med 2012;43:S8-23.

6. Catalano RF, Berglund ML, Ryan J, Lonczak HS, Hawkins D. Positive youth development in the United States: research findings on evaluations of positive youth development programs. Ann Am Acad Pol Soc Sci 2004;5:98-124.

7. Shek DT, Lee TY. Helping adolescents with greater psychosocial needs: subjective outcome evaluation based on different cohorts. ScientificWorldJ 2012;694018:1-10.

8. Shek DT. Qualitative evaluation of the training program of the Project P.A.T.H.S. in Hong Kong. Int J Adolesc Med Health 2010;22:425-35.
9. Eccles J, Gootman J, editors. Community programs to promote youth development. Washington, DC: National Academy Press, 2002.

10. Grigoroudis E, Siskos Y. Customer satisfaction evaluation: methods for measuring and implementing service quality. New York: Springer Science Business Media, 2010. DOI:10.1007/978-1-4419-1640-2.

11. Sabatelli RM, Anderson SA. Assessing outcomes in child and youth programs: a practical handbook (revised edition). Connecticut: US Department of Justice to the State of Connecticut, 2005.

12. Chen HT. Practical program evaluation: assessing and improving planning, implementation, and effectiveness. Thousand Oaks, CA: Sage, 2005.

13. Creemers BP. From school effectiveness and school improvement to effective school improvement: background, theoretical analysis, and outline of the empirical study. Educ Res Eval 2002;8:343-62.

14. Mark E. Student satisfaction and the customer focus in higher education. J Higher Educ Policy Manag 2013;35:2-10.

15. Lebow JL. Similarities and differences between mental health and health care evaluation studies assessing consumer satisfaction. Eval Program Plann 1983;6:237-45.

16. Hill N, Roche G, Allen R. Customer satisfaction: the customer experience through the customer's eyes. London: Cogent Publishing, 2007.

17. Fraser BJ. Research on classroom and school climate. In: Gabel D, editor. Handbook of research on science teaching and learning, New York: Macmillan, 1994:493-541.

18. Rossi PH. Program outcomes: conceptual measurement issues. In: Mullen EJ, Magnabosco JL, editors. Outcome measurement in the human services: cross-cutting issues and methods. Washington, DC: NASW Press, 1997:20-34.

19. Elliott KM. Key determinants of student satisfaction. J Coll Stud Ret 2003;4:271-79.

20. Sweeney L. A predictive model of student satisfaction. Irish J Acad Prac 2016;5:1-30. Available at: http://arrow.dit.ie/ijap/ vol5/iss1/8. Accessed: 28 Jun 2016.

21. Shek DT. Subjective outcome and objective outcome evaluation findings: Insights from a Chinese context. Res Soc Work Prac 2010;20:293-301.

22. Trotter C. What does client satisfaction tell us about effectiveness? Child Abuse Rev 2008;17:262-74.

23. Shek DT, Sun RC. Participants' evaluation of the project P.A.T.H.S.: are findings based on different datasets consistent? ScientificWorldJ 2012;187450:1-9.

24. Shek DT, Law MY. Evaluation of the Project P.A.T.H.S. based on the client satisfaction approach: view of the students. J Pediatr Adolesc Gynecol 2014;27:S2-9.

25. Shek DT, Ma CM, Xie QZ. Evaluation of a community-based positive youth development program based on Chinese junior school students in Hong Kong. Int J Adolesc Med Health 2016;1-9. DOI: 10.1515/ijamh-2017-3002.

26. Shek DT, Ma CM. Validation of a subjective outcome evaluation tool for participants in a positive youth development program in Hong Kong. J Pediatr Adolesc Gynecol 2014;27:S43-9.

27. Yu L, Shek DT. Testing factorial invariance across groups: an illustration using AMOS. Int J Disabil Hum Dev 2014;13:205-16.

28. Sim TN, Koh SF. A domain conceptualization of adolescent susceptibility to peer pressure. J Res Adolescence 2003;13:57-80.

29. Shek DT, Ma CM, Tang CY. Predictors of subjective outcome evaluation findings in a positive youth development program in Hong Kong. Int J Disabil Hum Dev 2011;10:249-55. 